\title{
AN EXPERIMENT IN TEXTILES.
}

THE work about to be described was the making of hot-dish holders by eight children of the second grade, aged six to eight years. The reason why it was made part of the school program was that it happened to be a problem in the social life of the children - one which they saw and felt, and one which made direct appeal to them without explanation or "presentation" by the teacher.

In planning it, the teacher's aims were (I) to give the children so much freedom that the conditions of work should present their own problems; (2) so to organize materials and processes as to give the greatest possible opportunity for initiation and originality; (3) to offer for choice such materials and processes as would bring the children in contact with suggestive and educative correlated subjects.

The children had been cooking out-of-doors in ovens which they had built for themselves, and in handling hot stones and utensils had felt the need of holders. Recognition of this need gave motive for all the work done, and made of it a social occupation rather than a "lesson in textiles." The children were asked what material they considered most suitable for the holders. This question made evident to both children and teacher the fact that they had little conscious knowledge of the qualities of fabrics, so they were given pieces of all kinds and qualities of textiles, with the idea of choosing the one best fitted to their purpose. During the examination and discussion of materials it was agreed that the one selected should be thick, and slow to burn. Examples of silk, wool, cotton, and linen were all selected because of their weight. Recognition of these different fabrics was then taught the children, and they were directed to compare them as to feel, smoothness, roughness, softness, and hardness, and as to luster or dulness. After some discussion, each child wrote on the blackboard the name of the fabric he considered best for the holder. As the words "cotton," "linen," "silk," and "wool" were all 
new, they had to be taught and, till they were learned, the lesson was one in writing and spelling. Each child's written vote was read and discussed by every other child, not merely for the sake of teaching reading, writing, and spelling, but because the practice of record-keeping even in its simplest form gave definiteness to the work and satisfied a certain business sense, which is strong in children of seven or eight years. So long as records were useful in the working out of problems, the teacher recognized the earliest need of a record and gave to the children the means of making one. This need, followed step by step, helped to give the children, almost unconsciously, the power of writing, which became to them a means of expression and a help to clearer thinking. None of the children in this case learned to write any one of the four words so that they could reproduce it without help, but many of them learned to recognize them at sight. The exercise was purposely made short, and the learning of words was not emphasized, for the teacher depended upon ( I) interest in the subject, (2) vividness of imagery, and (3) constant recurrence of the subject of thought for the ultimate perfect learning of the new words. The few words written were a record sufficient to show difference of opinion as to the material to be selected. As the various fabrics were equally heavy and thick, they were tested as to their readiness to burn. Thus wool was chosen as least combustible, and so most useful for their purpose. When the material was decided upon, the teacher proposed to the children that they should make some kind of a fabric for themselves rather than use the manufactured cloth. The prospect of doing a new kind of thing seemed promising, and the plan was unanimously accepted.

They were shown a fleece as the source of wool, and by touch discovered that the softest and thickest locks of wool were upon the back, shoulders, and sides of the sheep, and that the poorer quality was upon the breast and legs. For experiments in the making of yarn they were given locks of unwashed wool of several varieties, and they at once loosened the fibers, pulled them more or less straight, and twisted them together into a coarse, uneven thread. The making of yarn in this way proved interest- 
ing, and set the children to watching each other's results and comparing processes. At best it was seen to be slow.

This group of children had worked out some of the simple problems in the history of primitive peoples, and had spent three months in stories and lessons about the tree-men, cave-men, Indians, and Eskimos. They had had games, experiments, stories, and pictures to help in the making of theories as to origins of things and processes, such as the making of stone implements, fire, and pottery, and the preparation of food and clothing. The activities of the hunting stage in history had been, in experience or story, part of the school life. But at the time spinning was begun the history lessons moved from hunter life into the domestication of animals, herding, and the beginnings of shepherd life. While the children were twisting the wool fibers with their fingers, they were inventing theories as to how the same process was carried on by the earliest spinners. Upon deciding that they probably wound their thread upon a twig, the children were given little sticks upon which to wind theirs. The twisting threads set the stick whirling, and so by degrees led to the idea of the spindle. The children then made spindles of wood, and by this means spun a few yards of coarse, crude yarn.

They objected to the oil and dirt in the wool, and proposed washing it with soap. Those who chose hot water cleaned theirs most easily, and those who worked the wool too energetically discovered for the class the process of felting. Wool with all oil removed was found to spin less easily, so a little olive oil was used as a substitute for the natural oil, and the spinning was again made easier. Washing the wool, too, had matted it even in the cases where it was not fully felted, so hand-cards for combing and straightening the fibers were suggested. This simplified the process and introduced the children to a new stage in the evolution of textile machinery. At this point they were shown spinning-wheels under the hands of expert spinners, and should have been allowed to use the wheels, but that at the time was impossible. Other children of their age have used the large woolwheel with a fair degree of success.

By the time each child had spun his few yards of yarn it was 
agreed that the holders would be needed before sufficient yarn could be spun in this slow way. So the little already made was quickly woven into tiny rugs and taken to the playhouses at home.

A heavy, twisted, manufactured yarn was found for the holders, and, as it was undyed, the question of color was the first to be settled. The children were confident that dyeing the skeins would be a simple matter, and they brought for trial colored vegetables - roots, fruits, and berries - which, after free experimenting, all proved unsuccessful. These failures prepared the minds of the children for the idea of mordants, and when the practical effect of these was shown, the dyeing became more satisfactory.

With the laboratory experiments each child was taught to write some kind of a record, however simple. The one following is among the best, and was written after the series of dyeing lessons was finished. In the planning and discussion preparatory to this new idleas had been noted on the blackboard, and fragmentary records had been made, as indicated in the first lesson.

We dyed the wool for the holders. We first tried berries, willow bark, and colored chalk for dyes, but the wool did not hold the dyes. We tried an acid then an alkalai in the dye. The colors were not pretty and the dyes were not fast. Then we used logwood, fustic, madder, cochineal, and indigo for dyes. We boiled the wool in the mordant, then in the dye. I made old gold dye from fustic. Cochineal made crimson dye, madder red, logwood black. The indigo should have been blue, but it was gray.

When a sufficient number of fairly successful skeins had been dyed, combinations of two colors were made by each child, and with these two skeins - one for warp, and one for filling preparations were made for weaving the holders. In making the first little rug of their own yarn the children felt the necessity for some kind of a frame for stretching and holding firm the interlacing threads, and had suggested various simple devices for the purpose. As a means of teaching the simplest elements in weaving, the teacher showed the class how to sew warp onto a pasteboard card and darn the filling in and out with a long needle. Directions were then given, and each prepared a card for his own use. The problem was the drawing of a six-inch 
square in the center of a piece of heavy pasteboard; pointing off the edges of the square into quarter inches, and piercing through the points by means of a coarse darning needle. Through these perforations the heavy wool yarn was sewed in parallel lines on both sides of the card, making a double warp. Across one side of this warp, through the card, then across the other side of the warp, and back again, the filling thread was woven, or rather darned, leaving open one edge of the double warp, so that it could be removed from the pasteboard when finished. Both warp and filling threads were easily kept parallel, because the perforations in the card had been accurately made and were placed at exactly opposite points in the edges of the rectangle. A plain weavethat is, "one thread over and one down" - was all that was attempted by most of the children, but a few succeeded with a basket weave of "two over and two under."

The diagonal was not attempted in this first weaving. The card was cut away from the holder when the weaving was done, the edges of the open side were overhanded together, and the holder was finished as a thick, double, coarsely woven fabric of two contrasting colors, just six inches square.

Some time after the making of these holders it was proposed to the children that they weave rugs for the playhouses of the first-grade children. The suggestion met with enthusiastic approval. In planning this new venture they were asked how they could lessen the work in weaving, and what it was that took so much time in the making of the holders. One child said that it was "going under and over all the time with the needle." They were then asked to think of ways to lessen this labor, and, after much discussion and trial with material for constant experiment, they did work out the primitive idea of making, a shed by means of two sticks each to lift alternate threads of the warp. The alternate raising and lowering of a set of warp threads made it necessary to abandon the card as a loom, and quickly following came the idea of tying the warp to two fixed beams with space above and below. At this point they were shown the model of a wooden frame which had been made to combine all the points they had worked out, but with string substituted for one of the 
harness sticks. This was used as a pattern, and from it each child made a loom for his own use.

There was more dyeing of wool, this time single Germantown yarn. Combinations of three colors were made by each one, and with these colors designs for making the rugs were drawn and painted. The planning of pattern had to be directed by the teacher toward the making of simple geometrical forms possible in primitive weaving. They were changed as little as necessary, but were set in order and afterwards drawn the exact size planned for the rug.

White cotton carpet warp was tied on the beams of the newly made looms, and weaving began. Longer needles or shuttles were asked for and made in the shop. These were, however, cast aside soon for darning needles and packers' needles, because these latter were found more convenient in the working in of patterns. After the weaving was well under way, there was a visit to the Field Museum to look at Navajo weaving.

The little rugs, when finished and fringed, reached the proportions of about seven by ten inches, and showed a pattern worked in two or three colors, filling effect. They were finally given to the children of the first grade and used in their playhouses.

To give their work as much meaning as possible, the children were led to think of the way in which other people had done the same thing which they were doing. Much time and thought were spent on all the textile experiences of primitive peoples, because these could be understood and perhaps used by the children. The ancient Hebrews and present-day Arabs were chosen as illustrating simply the relation of the herding, weaving, and trading processes. The habits of their lives were told by means of stories and pictures. Bible stories of patriarchal life-Abraham, Isaac, Jacob, and Joseph - were read, told, and retold. Grassy plains, rolling hills, deserts, and oases were modeled on the sand-table by teacher and children as a necessary part of the history stories.

Toward the end of the time in which this work was being done the class decided to tell the stories to the children of other 
classes in the morning exercise. In planning the exercise they wrote such suggestions as this:

"I think it would be nice to make a little desert to show the children. We must have sand and rock, a tent and camels and flocks, and a well."

"We ought to have a mother and little girl weaving in front of the tent."

"We ought to tell how the shepherds drive their flocks to the grassy places in the desert. They travel at night because the days are hot. People in Arabia do not eat the same things we do. They eat dates and bread and cheese. They drink goats' milk. They grind their grain in a stone bowl. They do not have many dishes."

At the morning exercise the model of the desert was shown and explained by one of the children. He told about the wanderings of shepherds, their food, clothing, and customs. An eastern rug was shown, and its design and weave were explained. Then followed the stories of Abraham, Isaac, and Jacob. The children who told these stories had practiced them after carefully writing them. One is given as illustrative of the writing:

Abraham heard the voice of the Lord telling him to take his wife Sara, his nephew Lot, and all his herds, and journey to the land of Canaan. And the Lord promised Abraham that that land should belong to him and his sons forever. Abraham felt very badly because he had no sons. But the Lord promised him that his sons should be as many as the stars of heaven and as the sands of the sea.

So Abraham took his wife Sara and his nephew Lot, and all his flocks, and traveled to the land of Canaan. He traveled by night and followed the stars.

One day, as Abraham sat at his tent door, he saw three strangers appear. He went to meet them and invited them to enter his tent. He told his wife Sara to take quickly three measures of meal and cook cakes for the strangers. Then he ran to the flocks and chose the finest caif and told a young man to dress it for the strangers.

The strangers asked: "Where is thy wife Sara?" And they said that the next timc they passed that way Abraham should have a son. Sara was in her tent, and when she heard that she laughed. So when the son was born they called his name Isaac, for Isaac means "laughter."

Some use of arithmetic was involved in the measurement and weighing of the dye materials, and as the children lacked the necessary number knowledge, it was given in definite lessons before the dyeing was done. The problems which arose were:

I. Use of the metric scale and weights. 
2. Changing of rules intended for use in dyeing Ioo grams of wool to be used for 75 -gram skeins. This involved recognition of 75 as $3 / 4$ of 100 ; also that three-fourths of each rule should be used; the finding $3 / 4$ of $4,3 / 4$ of $12,3 / 4$ of $2,3 / 4$ of $8,3 / 4$ of 16 , $3 / 4$ of $40,3 / 4$ of 80 .

3. Drawing of a six-inch square in the center of a card.

4. Marking the edges of the square into quarter inches.

5. Estimating in yards, feet, and inches of the amount of yarn necessary for warp and filling of the six-inch holder, threads being one-fourth of an inch apart.

Clara Isabel Mitchell.

The University of Chicago

School of Education. 